\title{
Clinical characteristics and outcome of toxicity from Amanita mushroom poisoning
}

\author{
Satariya Trakulsrichai ${ }^{1,2}$ \\ Charuwan Sriapha ${ }^{2}$ \\ Achara Tongpoo ${ }^{2}$ \\ Umaporn Udomsubpayakul ${ }^{3}$ \\ Sunun Wongvisavakorn ${ }^{2}$ \\ Sahaphume Srisuma ${ }^{2,4}$ \\ Winai Wananukul ${ }^{2,4}$ \\ 'Department of Emergency Medicine, \\ ${ }^{2}$ Ramthibodi Poison Center, ${ }^{3}$ Section \\ for Clinical Epidemiology and \\ Biostatistics, Research Center, \\ ${ }^{4}$ Department of Medicine, Faculty \\ of Medicine, Ramathibodi Hospital, \\ Mahidol University, Bangkok, Thailand
}

This article was published in the following Dove Press journal:

International Journal of General Medicine

3 November 2017

Number of times this article has been viewed

Objective: To describe and analyze the clinical characteristics and outcome of amatoxin poisoning cases.

Methods: We performed a retrospective cohort study of amatoxin poisoning cases from Ramathibodi Poison Center Toxic Exposure Surveillance System, from May 2013 to August 2015.

Results: There were 30 consultations with a total of 55 poisoning cases. Most cases were male and from the north-east region. Hepatitis, acute kidney injury, jaundice, and coagulopathy accounted for $74 \%, 46.3 \%, 44.7 \%$, and $52.8 \%$ of the cases, respectively. Almost all of the patients were admitted to the hospital, and the median duration of hospital stay was found to be 4 days. Mortality rate was found to be $27.3 \%$. Most patients $(73 \%)$ received the treatment including multiple-dose activated charcoal (67.5\%), intravenous $\mathrm{N}$-acetylcysteine $(87.5 \%)$, and benzylpenicillin (45\%). In $60 \%$ of the cases, the treatment was initiated within $24 \mathrm{~h}$ after eating mushrooms. Exchange transfusion and liver transplantation were performed in one severe case. However, this patient died eventually. Because intravenous silybinin is not available in Thailand during the study period, 8 patients received oral silymarin instead. All 8 patients had hepatitis and were treated with high dosage of oral silymarin ( 5 patients with $4.48 \mathrm{~g} /$ day, 2 patients with $1.68 \mathrm{~g} /$ day, and 1 patient with $1.4 \mathrm{~g} /$ day) for a couple of days. One of these patients died as she received treatment very late; she was treated with silymarin at $1.68 \mathrm{~g} /$ day dosage. Thus, the fatality in oral silymarin treatment group was $12.5 \%$. We performed the analysis between the dead and survival groups. We found that in hepatitis, initial and maximum serum aspartate transaminase, initial and maximum serum alanine transaminase, and acute kidney injury were significantly different between the two groups.

Conclusion: Amanita mushroom poisoning caused high fatalities. Serum transaminase and creatinine were the factors associated with death. Treatment with oral high dose silymarin should be investigated further as one of the principal therapies in amatoxin poisoning.

Keywords: amatoxin, clinical characteristic, outcome, treatment, silymarin

\section{Introduction}

Cyclopeptide-containing species of mushroom including a large number of Amanita species such as Amanita phalloides, Amanita verna, and Amanita virosa are responsible for almost all mushroom-related fatalities. The toxic cyclopeptides in these mushrooms are amatoxins; amanitins are the most toxic that cause liver and kidney injury. ${ }^{1}$ Amatoxin poisoning is characterized by a long asymptomatic latency period followed by the gastrointestinal (GI) symptoms, transient improvement, severe hepatic and renal toxicity, and finally death. ${ }^{1,2}$ It is a medical emergency, which can cause

Correspondence: Satariya Trakulsrichai Department of Emergency Medicine, Faculty of Medicine, Ramathibodi Hospital, Mahidol University, Bangkok 10400, Thailand

Tel $+662201 \quad 1484$

Fax +6622012404

Email Satariya.tra@mahidol.ac.th 
serious illness and death of the individual. The currently available primary treatment strategies are intensive supportive care, detoxification procedures, and administration of chemotherapy. N-acetylcysteine, silibinin, thioctic acid, and antibiotics such as penicillin G, singly or in combination have been previously used to treat amatoxin poisoning, ${ }^{3,4}$ but unfortunately, its mortality rate is still high. ${ }^{1,2,4-9}$ The diagnosis and management of amatoxin poisoning is a challenging problem for physicians. Specific amatoxin antidote and the optimal management of its poisoning are still not determined. Nowadays, foraging and eating wild mushrooms is still popular in Thailand. However, the clinical data of amatoxin poisoning in our country and our region are limited. Thus, this is a review to ascertain the clinical characteristics, outcome, and factors associated with deaths of all amatoxin poisoning cases, which might be different from other regions.

\section{Materials and methods Study design}

This was a retrospective cohort study of a toxic surveillance system data (May 2013-August 2015) obtained from Ramathibodi Poison Center. Primary outcomes of this study were the clinical characteristics and the outcome of all amatoxin poisoning cases. The secondary outcome was the factors associated with patient mortality.

This study was approved by the Institutional Ethics Committee Board of Ramathibodi Hospital Faculty of Medicine, Mahidol University. Because this is a retrospective study that uses the preexisting confidential database from the poison center, which was previously recorded, patient consent was not required by our hospital's ethics committee board. The results of this study have been reported anonymously.

\section{Study setting and population}

The setting of the study was a poison center of a tertiary teaching hospital with approximately 15,000-20,000 consultations/year, most consultations were from medical personnel.

Based on the inclusion criteria, all amatoxin exposure cases consulted to Ramathibodi Poison Center were included in this study. The diagnosis of amatoxin-containing mushroom poisoning was based on clinical data including a history of mushroom ingestion and delayed onset ( $>5 \mathrm{~h}$ ) of GI symptoms after consumption and/or elevated liver enzymes. Patients who had a history of mushroom ingestion and elevated liver enzymes without other explainable causes were also included in this study. If one patient presented with typical clinical picture of amatoxin poisoning (such as GI symptoms and hepatitis), the other cases who ingested mushrooms together with that patient were included in our data and this was defined as the group of poisoning. Cases in which mushrooms were coingested with drugs or other substances were excluded from the analysis.

\section{Study protocol}

We collected the data of those cases which met the inclusion and exclusion criteria. Demography, medical history, clinical features, laboratory results, treatment modalities, follow-up details, final diagnosis, and outcome data were collected.

Hypotension was defined as systolic blood pressure less than $90 \mathrm{mmHg}$. Jaundice was defined as a clinical finding on examination and with a specific bilirubin level (plasma bilirubin level more than $1.5 \mathrm{mg} / \mathrm{dL}$ ). Hypoglycemia was positive if a plasma glucose level was less than $60 \mathrm{mg} / \mathrm{dL}$ or from the data recorded when the follow-up call was done. Coagulopathy was defined as an international normalized ratio (INR) greater than 1.5. Acute kidney injury (AKI) was diagnosed on the basis of clinical history and laboratory data (the Acute Kidney Injury Network criteria). We assumed that all patients without underlying diseases were healthy and might have the normal kidney function prior to the consultation.

We used SPSS version 18 to analyze the data. Mean and standard deviation were analyzed for continuous data and the frequency and percentage for categorical data. Comparisons between the groups were performed by using Student's $t$-test if data were normally distributed and Mann-Whitney $U$ test otherwise. The differences in categorical variables were evaluated by the chi square analysis and Fisher's exact test. $P$ values less than 0.05 were accepted as statistically significant.

\section{Results}

There were a total of 30 consultations with 55 poisoning cases. Forty patients (72.7\%) presented for consultation along with other family members or friends who had the same symptoms after taking the meal with the mushrooms; these were considered together as poisoning groups. Except one, all poisoning cases were found during May to September each year (2013-2015). In one case, the mushroom was identified by an experienced mycologist. The circumstances under which poisoning occurred were all unintentional and accidental. The clinical characteristics 
Table I Baseline characteristics of the patients

\begin{tabular}{|c|c|}
\hline Characteristics & $\begin{array}{l}\text { Number of } \\
\text { patients }\end{array}$ \\
\hline \multicolumn{2}{|l|}{ Gender } \\
\hline Male & $28(50.9 \%)$ \\
\hline Female & 27 (49.1\%) \\
\hline Age (year), mean $\pm S D$ & $43.85 \pm 21.65$ \\
\hline \multicolumn{2}{|l|}{ Region } \\
\hline North/east & 39 (7I\%) \\
\hline North & 7 (I2.7\%) \\
\hline West & $6(10.9 \%)$ \\
\hline East & $2(3.6 \%)$ \\
\hline Central & $\mathrm{I}(\mathrm{I} .8 \%)$ \\
\hline \multicolumn{2}{|l|}{ Underlying diseases } \\
\hline No & $46(83.6 \%)$ \\
\hline Yes & $9(16.4 \%)$ \\
\hline $\begin{array}{l}\text { The onset of Gl symptoms after consuming mushrooms } \\
\text { (hours), median (min-max) }\end{array}$ & $9(0.5-24)$ \\
\hline \multicolumn{2}{|l|}{$\begin{array}{l}\text { Time between consumption of mushrooms and hospital } \\
\text { admission ( } 5 \text { I cases) }\end{array}$} \\
\hline Within 24 hours & 19 (37.3\%) \\
\hline More than 24 hours & 32 (62.7\%) \\
\hline \multicolumn{2}{|l|}{ Admitted to the hospital } \\
\hline Yes & $5 \mathrm{I}(92.7 \%)$ \\
\hline No & $4(7.3 \%)$ \\
\hline
\end{tabular}

Abbreviations: SD, standard deviation; Gl, gastrointestinal ; min, minimum; max, maximum.

Table 2 The clinical features of the patients during the hospitalization

\begin{tabular}{ll}
\hline Clinical features (total cases recorded) & $\begin{array}{l}\text { Number of } \\
\text { patients (\%) }\end{array}$ \\
\hline Hepatitis (50 cases) & $37(74 \%)$ \\
AKI (54 cases) & $25(46.3 \%)$ \\
Jaundice (47 cases) & $21(44.7 \%)$ \\
Coagulopathy (36 cases) & $19(52.8 \%)$ \\
Elevated indirect bilirubin (>50\% of total) (48 cases) & $13(27 \%)$ \\
Bleeding (all had GI bleeding) (53 cases) & $12(22.6 \%)$ \\
Hepatic encephalopathy (53 cases) & $11(20.8 \%)$ \\
\hline
\end{tabular}

Abbreviations: AKI, acute kidney injury; GI, gastrointestinal.

and demographic data are shown in Table 1. The underlying diseases reported were chronic alcohol drinking, hypertension, diabetes, and chronic kidney disease. Even, some patients showed the onset of GI symptoms after consuming mushrooms less than 5 hours, they all had history of mushroom consumption and developed hepatitis during hospitalization with exclusion of other possible causes. Thirty-two patients (58.2\%) presented to the hospital to see the physician after the start of their symptoms, but they were not recognized by the physicians that they were intoxicated by the mushroom, and some of these patients were managed as outpatients. There was one case of pregnant
Table 3 Laboratory findings of all patients

\begin{tabular}{|c|c|}
\hline Laboratory finding & Results \\
\hline Initial AST results (IU/L), median (min-max) & $159.5(18-12,592)$ \\
\hline Max AST results (IU/L), median (min-max) & $871(18-12,592)$ \\
\hline Initial ALT results (IU/L), median (min-max) & $122(|2-| 8,87 \mid)$ \\
\hline Max ALT results (IU/L), median (min-max) & $\mid 426.5(|2-| 8,87 \mid)$ \\
\hline $\begin{array}{l}\text { Max total bilirubin results }(\mathrm{mg} / \mathrm{dL}), \text { median } \\
(\min -\max )\end{array}$ & $1.4(0.19-28.3)$ \\
\hline $\begin{array}{l}\text { Max direct bilirubin results }(\mathrm{mg} / \mathrm{dL}), \text { median } \\
(\min -\max )\end{array}$ & $0.5(0.1-18.49)$ \\
\hline Max INR results, median (min-max) & $\mathrm{I} .43(0.95-2 \mathrm{I} .67)$ \\
\hline Max creatinine results $(\mathrm{mg} / \mathrm{dL})$, median (min-max) & $1.13(0.33-7.8)$ \\
\hline
\end{tabular}

patient who was in the gestational age of about 26 weeks at that time; however, she finally survived.

The clinical features of all cases during the hospital stay are shown in Table 2 in which hepatitis was the most common clinical syndrome. Patients who developed the abnormal bleeding all showed bleeding in GI tract with or without other sites of bleeding. Two cases presented with hypotension at the first visit to the hospital. The patients, who had normal liver enzymes at presentation, also developed hepatitis $2.1 \pm 0.67$ days after ingestion. In acute liver failure cases, hepatic encephalopathy developed about $4.2 \pm 1.33$ days after ingestion. The mortality rate during the study period was found to be $27.3 \%$ ( 15 cases).

Laboratory results of all patients are reported in Table 3. For the treatment modalities, 15 patients $(27.3 \%)$ received only the supportive treatment. In $60 \%$ of the cases (33 cases), the treatment was initiated within $24 \mathrm{~h}$ after eating mushrooms. Other treatment regimens followed were multiple-dose activated charcoal (MDAC) (27 cases, 49.1\%), intravenous $\mathrm{N}$-acetylcysteine (NAC) (35 cases, 63.6\%), intravenous benzylpenicillin of 300,000-1,000,000 units/ $\mathrm{kg}$ (18 cases, $32.7 \%$ ), and oral high dose silymarin ( 8 cases, $14.5 \%)$. A 2-year-old female, whose case was serious, was treated with MDAC, intravenous NAC and blood exchange transfusion. She also underwent partial liver transplantation from her relative; however, she eventually died.

The dosage of oral high dose silymarin varied: $4.48 \mathrm{~g} /$ day in 5 cases, $1.68 \mathrm{~g} /$ day in 2 cases, and $1.4 \mathrm{~g} /$ day in 1 case. The overall treatment duration was about 3 days. All patients who underwent the aforementioned treatments had hepatitis and were diagnosed as the poisoning group. The following clinical features of the silymarin cases were found: AKI, $50 \%$; coagulopathy, 37.5\%; jaundice, abnormal bleeding, and hepatic encephalopathy accounted for $25 \%$ each. One patient from 
Table 4 The mortalities based on the mode of treatment for the patients

\begin{tabular}{|c|c|}
\hline Mode of treatment (total cases treated) & $\begin{array}{l}\text { Number of } \\
\text { deaths (\%) }\end{array}$ \\
\hline Supportive therapy only (I5 cases) & $3(20 \%)$ \\
\hline \multicolumn{2}{|l|}{ The treatment regimen } \\
\hline MDAC in the regimen ( 27 cases) & $5(18.5 \%)$ \\
\hline NAC in the regimen ( 35 cases) & $12(34.3 \%)$ \\
\hline Pen $G$ in the regimen ( 18 cases) & $4(22.2 \%)$ \\
\hline Oral silymarin in the regimen ( 8 cases) & I (I2.5\%) \\
\hline \multicolumn{2}{|l|}{ Single therapy } \\
\hline NAC alone ( 7 cases) & $4(57.1 \%)$ \\
\hline Oral silymarin alone ( $\mathrm{I}$ case) & $0(0 \%)$ \\
\hline MDAC alone ( $\mathrm{I}$ case) & $0(0 \%)$ \\
\hline \multicolumn{2}{|l|}{ Double therapy } \\
\hline MDAC + NAC (7 cases) & $3(42.9 \%)$ \\
\hline MDAC + Pen G ( 2 cases $)$ & 0 \\
\hline NAC + Pen G (3 cases) & $3(100 \%)$ \\
\hline Oral silymarin + NAC (2 cases) & 0 \\
\hline \multicolumn{2}{|l|}{ Triple and quadruple therapy } \\
\hline MDAC + NAC + Pen G (12 cases $)$ & I (8.3\%) \\
\hline Oral silymarin + MDAC + NAC (4 cases) & I (25\%) \\
\hline Oral silymarin + MDAC + NAC + Pen G (I case) & 0 \\
\hline
\end{tabular}

Abbreviations: MDAC, multiple-dose activated charcoal; NAC, $\mathrm{N}$-acetylcysteine intravenous; Pen G, penicillin G; Oral silymarin, oral high dose silymarin.

this group died; nevertheless, she was treated more than 48 hours after consuming mushrooms, which was considered late.

The mortality rate was analyzed and classified by the mode of treatment (Table 4). When we excluded the mode of treatment, which had only a few cases in those groups, we found that giving NAC alone caused the highest fatality
(57.1\%). The patients who received MDAC and oral silymarin in their treatment regimen had $18.5 \%$ and $12.5 \%$ mortality rate, which was lower than that of only supportive treatment. The patients who were treated with triple therapy including MDAC, NAC, and penicillin G had the lowest mortality at $8.3 \%$.

We compared the clinical characteristics and laboratory findings between the patients who died and survived to analyze the factors associated with deaths. We performed the analysis for all patients and for only those patients who developed hepatitis. In case of both all patients and patients with hepatitis, the differences in the following parameters were found to be statistically significant between dead and surviving patients: initial and maximum aspartate aminotransferase (AST) results, initial and maximum alanine aminotransferase (ALT) results, maximum creatinine results, maximum total bilirubin results, maximum direct bilirubin results, AKI, jaundice, and coagulopathy (Table 5). However, age $(0.344,0.190)$, sex $(1,0.97)$, onset of GI symptoms $(0.433,0.649)$, interval from eating mushrooms to hospital admission $(0.176,0.429)$, having fever during hospitalization $(0.134,0.215)$, increased indirect bilirubin $(>50 \%$ of total bilirubin) $(0.298,0.475)$, different types of therapies (MDAC [0.09, 0.081], NAC [0.434, 0.434], penicillin G $[0.119,0.727]$, and oral silymarin [0.423, 0.423]) showed no statistically significant differences in both all patients and in patients with hepatitis.

Table 5 The statistically significant differences of the clinical characteristics and the laboratory findings between the fatality and the survival group for every patient and for only the patients who developed hepatitis

\begin{tabular}{|c|c|c|c|c|c|c|}
\hline \multirow[t]{2}{*}{ Clinical characteristics } & \multicolumn{3}{|l|}{ All patients } & \multicolumn{3}{|c|}{ Patients with hepatitis } \\
\hline & $\begin{array}{l}\text { Patients who } \\
\text { survived (40) }\end{array}$ & $\begin{array}{l}\text { Patients who } \\
\text { died (15) }\end{array}$ & $\overline{p \text { value }}$ & $\begin{array}{l}\text { Patients who } \\
\text { survived (23) }\end{array}$ & $\begin{array}{l}\text { Patients who } \\
\text { died (14) }\end{array}$ & $p$ value \\
\hline AKI (\%) & I I/39 (28.2\%) & I4/I5 (93.3\%) & $<0.001$ & $10 / 23(43.5 \%)$ & $13 / 14$ (92.9\%) & 0.003 \\
\hline Jaundice (\%) & $9 / 34(26.5 \%)$ & $12 / 13(92.3 \%)$ & $<0.001$ & $7 / 22(31.8 \%)$ & $12 / 13(92.3 \%)$ & 0.001 \\
\hline Coagulopathy (\%) & $6 / 23(26.1 \%)$ & $13 / 13(100 \%)$ & $<0.001$ & $5 / 14(35.7 \%)$ & $13 / 13(100 \%)$ & 0.001 \\
\hline $\begin{array}{l}\text { Initial AST results (IU/L), } \\
\text { median (min-max) }\end{array}$ & $42.5(18-5,500)$ & $2,350(44-12,592)$ & $<0.001$ & $61(2 \mid-5,500)$ & $3,137(289-12,592)$ & $<0.001$ \\
\hline $\begin{array}{l}\text { Initial ALT results (IU/L), } \\
\text { median (min-max) }\end{array}$ & $44.5(12-6,268)$ & I,787 (23-|8,87I) & $<0.001$ & $68(13-6,268)$ & $2,100(200-|8,87|)$ & $<0.001$ \\
\hline $\begin{array}{l}\text { Max AST results (IU/L), } \\
\text { median (min-max) }\end{array}$ & $323(18-12,300)$ & $5,750(2,64|-| 2,592)$ & $<0.001$ & $532(135-12,300)$ & $5,750(2,64 I-12,592)$ & $<0.001$ \\
\hline $\begin{array}{l}\text { Max ALT results (IU/L), } \\
\text { median (min-max) }\end{array}$ & $45 \mid(12-9,899)$ & $3,436.5(|, 684-| 8,87 \mid)$ & $<0.001$ & $607(76-9,899)$ & $3436.5(1,684-|8,87|)$ & $<0.001$ \\
\hline $\begin{array}{l}\text { Max total bilirubin results } \\
(\mathrm{mg} / \mathrm{dL}) \text {, median (min-max) }\end{array}$ & $1.2(0.19-17.9)$ & $6.56(0.5-28.3)$ & 0.011 & $1.34(0.23-17.9)$ & $6.56(0.5-28.3)$ & 0.004 \\
\hline $\begin{array}{l}\text { Max direct bilirubin results } \\
(\mathrm{mg} / \mathrm{dL}) \text {, median (min-max) }\end{array}$ & $0.4(0.1-12.75)$ & $3.2(0.2-18.49)$ & $<0.001$ & $0.5(0.1-12.75)$ & $3.2(0.2-18.49)$ & 0.001 \\
\hline $\begin{array}{l}\text { Max creatinine results } \\
(\mathrm{mg} / \mathrm{dL}), \text { median (min-max) }\end{array}$ & $0.9(0.33-3.9)$ & $3.5(0.4-7.8)$ & $<0.001$ & $0.9(0.33-3.9)$ & $3.5(0.4-7.8)$ & $<0.001$ \\
\hline
\end{tabular}

Abbreviations: AST, aspartate aminotransferase; ALT, alanine transaminase; AKI, acute kidney disord ; min, minimum; max, maximum. 


\section{Discussion}

In our study, the diagnosis of the amatoxin poisoning was based on the history and symptoms without amanitin confirmation. However, most of our cases exhibited hepatitis after the ingestion and exposure as a group of poisoning. It might help to confirm the diagnosis of poisoning even though no definite investigation could be performed. The consultations to our poison center were from every province in Thailand, so our data might represent the picture of this type of poisoning for the whole country. The majority of patients were from northeastern region which correlated with the wild mushroom foraging culture of the people in this region and occurred mostly during rainy season which is the growing season of mushrooms. Most were admitted to hospitals quite late. We proposed that some patients visited to the hospital late, which might be due to their lack of concern of poisoning. Even some patients went to the hospital because of the GI symptoms, and we found that some physicians could not diagnose for this type of poisoning. This might be because the first phase of the poisoning was nonspecific symptoms and liver function test might not be the routine laboratory test to be checked.

The clinical features found in this study such as hepatitis, AKI, jaundice, and coagulopathy matched with the typical clinical symptoms of this poisoning. ${ }^{1}$ Hepatitis and hepatic encephalopathy developed about 2 and 4 days after ingestion. Interestingly, we found that some patients developed increased value of indirect bilirubin $(>50 \%$ of total bilirubin) during their hospitalization, which was not frequently mentioned as a strong clinical evidence in previous studies. Hemolysis was not obviously indicated as an etiology in our data. However, our patients' data might not be complete or these patients might not be fully investigated to find out the etiologies of elevated indirect bilirubin. In a very severe case, the patient demonstrated significant elevation of indirect bilirubin for which she underwent treatment. She did not have obvious evidence of hemolysis. Thus, the pathophysiology of this abnormal finding should be explored in the future.

The mortality in our study was about $30 \%$, which was found to be higher than most other studies. ${ }^{1,2,4-8}$ The recent data from the annual report of the American Association of Poison Control Centers showed low fatality as less than $10 \% .^{10-12}$ Our finding on higher mortality may be due to the selection bias in which severe cases would be consulted to our poison center or from the different ethnicities of the studied patients. Because of the high fatality, therefore, the public education for wild mushroom picking, especially before the beginning of the rainy season, might play an important role in the prevention of this kind of poisoning.

The factors associated with deaths found from our data were initial and maximum AST and ALT concentrations, maximum creatinine concentrations, AKI, jaundice, and coagulopathy, which were consistent with other studies' results. ${ }^{2,3,6,7,13}$ However, we did not study other laboratories parameters that might play a role in the prognosis of amatoxin poisoning, such as alkaline phosphatase and lactate dehydrogenase $\mathrm{e}^{3}$ because of our incomplete data.

Among the treatment modalities studied, lowest mortality $(8.3 \%)$ was found in the patients who underwent triple chemotherapy with MDAC, NAC, and penicillin G. In case of overall mortality, the patients who were treated with oral silymarin or MDAC in the treatment regimens showed the low mortalities ( $12.5 \%$ and $18.5 \%$, respectively) when compared to the supportive treatment only. Unexpectedly, we found that the treatment with NAC alone or in the treatment regimen caused the highest mortality. This finding was different from others studies ${ }^{3,4}$ which showed lower mortalities than this study. The explanation for this difference might be from the severity of the patients or the small number of cases in this study.

Silymarin is the extract from milk thistle, Silybum marianum. ${ }^{14}$ Silibinin is one of the interesting principal agents that has been extensively studied for amatoxin mushroom poisoning. ${ }^{3,7,15,16}$ During the study period, silibinin for intravenous route was not available in Thailand. Thus, the treatment which Ramathibodi Poison Center advised might include oral high dose silymarin (instead of silibinin) combined with other chemotherapies in some patients. Oral high dose silymarin used in the regimen of the treatment was proposed and estimated from the recommended dose of intravenous silibinin, oral bioavailability, ${ }^{1,16}$ and the amount of silibinin in the marketed products. From the results of this study, even the patient who received this treatment had the lower fatality than the supportive treatment group. However, they also received other treatment regimens and no statistical significance was demonstrated between the survival and death based on the treatment received. Because of the small number of cases, we cannot confirm the efficacy of oral silymarin. Nevertheless, in this study, we did not observe any adverse effects from this high dose silymarin. Thus, more studies are needed to clarify the efficacy of this medication.

Our study had some limitations which can be listed as follows: First, our study was the retrospective study which 
might have contained some incomplete data. Medical history was obtained from patients, which they recognized, reported to the medical personnel; therefore, sometimes this might not be clearly or completely accurate. Second, a small number of patients' data were included in this study. Finally, there was no laboratory test performed to confirm the definite diagnosis of alpha-amanitin or the identification of mushrooms.

\section{Conclusion}

Amanita mushroom poisoning caused high fatalities in Thailand. Serum transaminase and creatinine were the factors associated with death. Treatment with oral high dose silymarin should be investigated further as an adjunctive therapy in amatoxin poisoning based on its cost and ease of availability.

\section{Acknowledgment}

The authors express sincere thanks to Professor Amnuay Thithapandha for his help with English editing and comments on the manuscript.

\section{Disclosure}

The authors declare that they do not have any conflicts of interest with respect to the silymarin product. The authors report no other conflicts of interest in this work.

\section{References}

1. Garcia J, Costa VM, Carvalho A, et al. Amanita phalloides poisoning: mechanisms of toxicity and treatment. Food Chem Toxicol. 2015;86:41-55.

2. Trabulus S, Altiparmak MR. Clinical features and outcome of patients with amatoxin-containing mushroom poisoning. Clin Toxicol (Phila). 2011;49(4):303-310.
3. Enjalbert F, Rapior S, Nouguier-Soulé J, Guillon S, Amouroux N, Cabot C. Treatment of amatoxin poisoning: 20 -year retrospective analysis. $J$ Toxicol Clin Toxicol. 2002;40(6):715-757.

4. Poucheret P, Fons F, Doré JC, Michelot D, Rapior S. Amatoxin poisoning treatment decision-making: pharmaco-therapeutic clinical strategy assessment using multidimensional multivariate statistic analysis. Toxicon. 2010;55(7):1338-1345.

5. Schenk-Jaeger KM, Rauber-Lüthy C, Bodmer M, Kupferschmidt H, Kullak-Ublick GA, Ceschi A. Mushroom poisoning: a study on circumstances of exposure and patterns of toxicity. Eur J Intern Med. 2012;23(4):e85-e91.

6. Fantozzi R, Ledda F, Caramelli L, et al. Clinical findings and follow-up evaluation of an outbreak of mushroom poisoning--survey of Amanita phalloides poisoning. Klin Wochenschr. 1986;64(1):38-43.

7. Ganzert M, Felgenhauer N, Zilker T. Indication of liver transplantation following amatoxin intoxication. J Hepatol. 2005;42(2):202-209.

8. Giannini L, Vannacci A, Missanelli A, et al. Amatoxin poisoning: a 15 -year retrospective analysis and follow-up evaluation of 105 patients. Clin Toxicol (Phila). 2007;45(5):539-542.

9. Jacobs J, Von Behren J, Kreutzer R. Serious mushroom poisonings in California requiring hospital admission, 1990 through 1994. West $J$ Med. 1996;165(5):283-288.

10. Mowry JB, Spyker DA, Brooks DE, McMillan N, Schauben JL. 2014 Annual Report of the American Association of Poison Control Centers' National Poison Data System (NPDS): 32nd Annual Report. Clin Toxicol (Phila). 2015;53(10):962-1147.

11. Mowry JB, Spyker DA, Cantilena LR Jr, Bailey JE, Ford M. 2012 Annual Report of the American Association of Poison Control Centers" National Poison Data System (NPDS): 30th Annual Report. Clin Toxicol (Phila). 2013;51(10):949-1229.

12. Mowry JB, Spyker DA, Cantilena LR Jr, McMillan N, Ford M. 2013 Annual Report of the American Association of Poison Control Centers' National Poison Data System (NPDS): 31 st Annual Report. Clin Toxicol (Phila). 2014;52(10):1032-1283.

13. Krenová M, Pelclová D, Navrátil T. Survey of Amanita phalloides poisoning: clinical findings and follow-up evaluation. Hum Exp Toxicol. 2007;26(12):955-961.

14. Surai PF. Silymarin as a natural antioxidant: an overview of the current evidence and perspectives. Antioxidants (Basel). 2015;4(1):204-247.

15. Gores KM, Hamieh TS, Schmidt GA. Survival following investigational treatment of amanita mushroom poisoning: thistle or shamrock? Chest. 2014;146(4):e126-e129.

16. Mengs U, Pohl RT, Mitchell T. Legalon ${ }^{\circledR}$ SIL: the antidote of choice in patients with acute hepatotoxicity from amatoxin poisoning. Curr Pharm Biotechnol. 2012;13(10):1964-1970.
International Journal of General Medicine

\section{Publish your work in this journal}

The International Journal of General Medicine is an international, peer-reviewed open-access journal that focuses on general and internal medicine, pathogenesis, epidemiology, diagnosis, monitoring and treatment protocols. The journal is characterized by the rapid reporting of reviews, original research and clinical studies across all disease areas.

\section{Dovepress}

The manuscript management system is completely online and includes a very quick and fair peer-review system, which is all easy to use. Visit http://www.dovepress.com/testimonials.php to read real quotes from published authors. 